\title{
FRAMEWORK FOR SECURING EDUCATIONAL E-GOVERNMENT SERVICE
}

\author{
Mr. Tesfayee Meshu ${ }^{1}$ and Dr. G Sanjiv Rao ${ }^{2}$ \\ ${ }^{1}$ Head of the Department, Department of Computer Science \& Information Technology \\ and Software Engineering, School of Electrical Engineering \& Computing, Addis Ababa \\ Science \& Technology University, Ethiopia. \\ ${ }^{2}$ Associate Professor, Department of Computer Science \& Information Technology and \\ Software Engineering, School of Electrical Engineering \& Computing, Addis Ababa \\ Science \& Technology University, Ethiopia.
}

\begin{abstract}
Enhancement in technology is leading to a change in the way governments, individuals, institutions and business entities provide quality services to the citizen. Today's education system plays crucial role for developing cognizance in society so e-government service is obliged to integrate with educational system. In this work we proposed a novel framework for integrating educational service within e-government services. One of the main tasks of this paper is to explore or propose a Secure Examination Management System (SEMS). The system has been designed using cryptographic primitives, which enables students to take the exam from anywhere. The student is allowed to take the exam after he gives his necessary authentication details. In SEMS, it is important to exclude false students while ensuring the privacy for the honest students. It allows evaluators to share student examination papers for evaluation with proper authentication. This is done using digital signatures, authentication and confidentiality provided by public key cryptographic system.
\end{abstract}

\section{KEYWORDS}

Framework, Educational System, Secure Examination, E-government services, Encryption, Examination Server, Authentication.

\section{INTRODUCTION}

In today's society, e-government and digital government are those terms that are used to describe the application of information and communication technologies (ICTs) to improve public services, educational services and to increase citizen participation in democratic government [1]. In most of the countries, e-government has been the dominant term used for policy-making. This term gives emphasis on user-centric services that can be integrated to support easy and efficient use of services by citizens, businesses and education services as shown in Fig.1. 


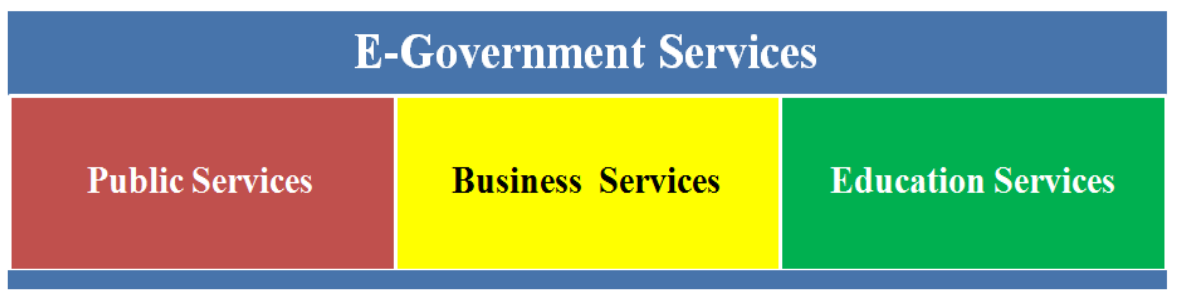

Fig.1. E-government Service Components

\subsection{E-Government Services}

Electronic Government or e-government is at the forefront of current public sector reform policies across the world, where the use of computer-based information and communication technologies (e.g. telecom networks, computers and mobile phones) to deliver public services in the public sector is seen as a major leverage of public sector innovation. E-Government is usually seen as using ICT in order to provide easy and very efficient access to government information and services to the citizens, businesses and government agencies and also improve the quality of services, by increased speed and efficiency, provide citizens with the opportunities to participate in different kinds of democratic processes [2]. The digital interactions between a citizen and their government $(\mathrm{C} 2 \mathrm{G})$, between governments and government agencies $(\mathrm{G} 2 \mathrm{G})$, between government and citizens (G2C), between government and employees (G2E), and between government and businesses/commerce (G2B). Essentially, e-government delivery models can be broken down into the following categories [3], which shown in Fig.2.

- $\mathrm{G} 2 \mathrm{G}$ (government to governments)

- $\mathrm{G} 2 \mathrm{C}$ (government to citizens)

- $\mathrm{G} 2 \mathrm{E}$ (government to employees)

- G2B (government to businesses)

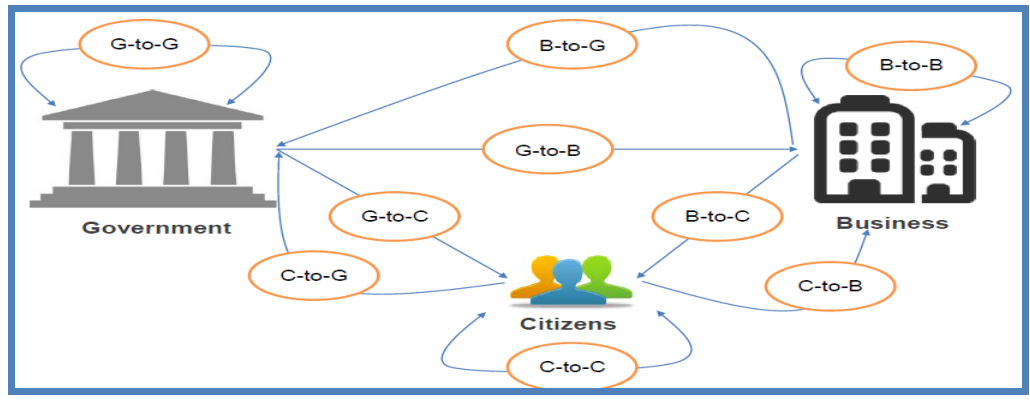

Fig.2. Digital interactions between e-government service components

\subsection{Benefits of E-Government Services}

So many authors explained about the use of the e-government services in their tasks. Accordingly the benefits of these services are described in [4] as follows.

- Huge or large benefits are offered by the e-government for citizens through: It is providing the every government information and services through a single window. It 
allows more flexibility and convenience for most of the government offices and agencies, through online access of services. Here, it meets the target of minimizing the turn-around time for citizens in the provision of every government services.

- Businesses also benefited by it: e-government is serving as a gateway for the mutual development and beneficial interactions between the government and businesses. It is eliminating the administrative procedures when dealing with the government, thus resulting in considerable time and costs savings for the businesses; and providing a secure and trustworthy environment for conducting online transactions with the government.

- An E-Government service helps the government by: It is improving the means of providing information sharing and communication among all those government offices that belongs. As the result of this, there is a major enhancement in the organization of most public sector resources. Here, it avails more tools in order to solve the raising number of problems that facilitates efficiency of related issues.

\subsection{Need of E-Government Services in Education System}

Education is the key service in the society where we are living. There is no question about the importance of this sector for the society. Unfortunately, no emphasis is given to incorporate it to the e-government services. In this sector, there is a high competition among the students for to be employed but most of the tasks are within the government offices. By incorporating this sector, we can improve issues like vacancy and their exam requirements.

Using ICT as a means, education is becoming moving from a knowledge-transfer model to a collaborative, active, self-directed, and engaging model that helps students increase their knowledge and develop the skills needed to succeed in the "Learning Society [5]. So the need of e-government services in education system plays a vital role in the present society.

Technology is just one of many methods that have its own contribution in education today [5]. This is to say we are living in the age where the assets of information and the acquiring of new things bring its own impact on educational institutions to rethink the means of teaching and learning in a global market. Accordingly, this system also needs to follow an appropriate guidelines and one of the major element from this service is delivering its assessment sub service in a secured way.

But from our discussions, reading and revision so far no one: be it an individual, public and private sectors give an appropriate emphasis on educational systems especially on making the exams at different stages of educational hierarchy to be a secured one. So, the purpose of this study is to build an initial framework to secure the sub service of the educational system.

\section{Literature REVIEW}

Steve Harrison [6] tried to develop a framework by utilising the Open Web Application Security Project's (OWASP) Application Security Verification Standard (ASVS). The author in his work focused on developing his own security framework that can be used within Agile sprints to develop secure applications and to give assurance to the business owner that any technical risks have been mitigated.

Geoffrey Rwezaura [7] focused on proposing a framework for enhancing services in government to efficiently offer secure way of e-government services. He came up with a new approach by 
incorporating security services into eGMMs. In addition, he enhanced the awareness, need and importance of security services to be an integral part of eGMMs to different groups such as research organizations, academia, practitioners, policy and decision makers, stakeholders, and the community.

Min-Shiang HWANG [8] proposed a classification of e-government applications and some problems in e-government by considering from the four perspectives such as technical, political, cultural, and legal aspects.

However; in all the above tasks the authors in their research strategies did not take into consideration about the education system in e- government services, which we believe that this is one of the important sectors to be considered. Besides, there is no task so far on the secured based framework on this area.

\section{The Proposed Framework}

Framework is always needed to do tasks as per their standards; hence we came up with the framework that facilitates to conduct secured exams as shown in Fig.3. The proposed framework addresses the integration of educational service within the existing e-government services. The framework was developed with the intension of responding to the inefficient and weak privacy checking systems of conducting exams in government educational system. The Secure Exam Management System (SEMS) will be assumed to serve as a benchmark for conducting secured examination in educational e-government services. This helps to improve the standard of conducting examination for the entire educational system in the present and puts great milestone for the upcoming society too.

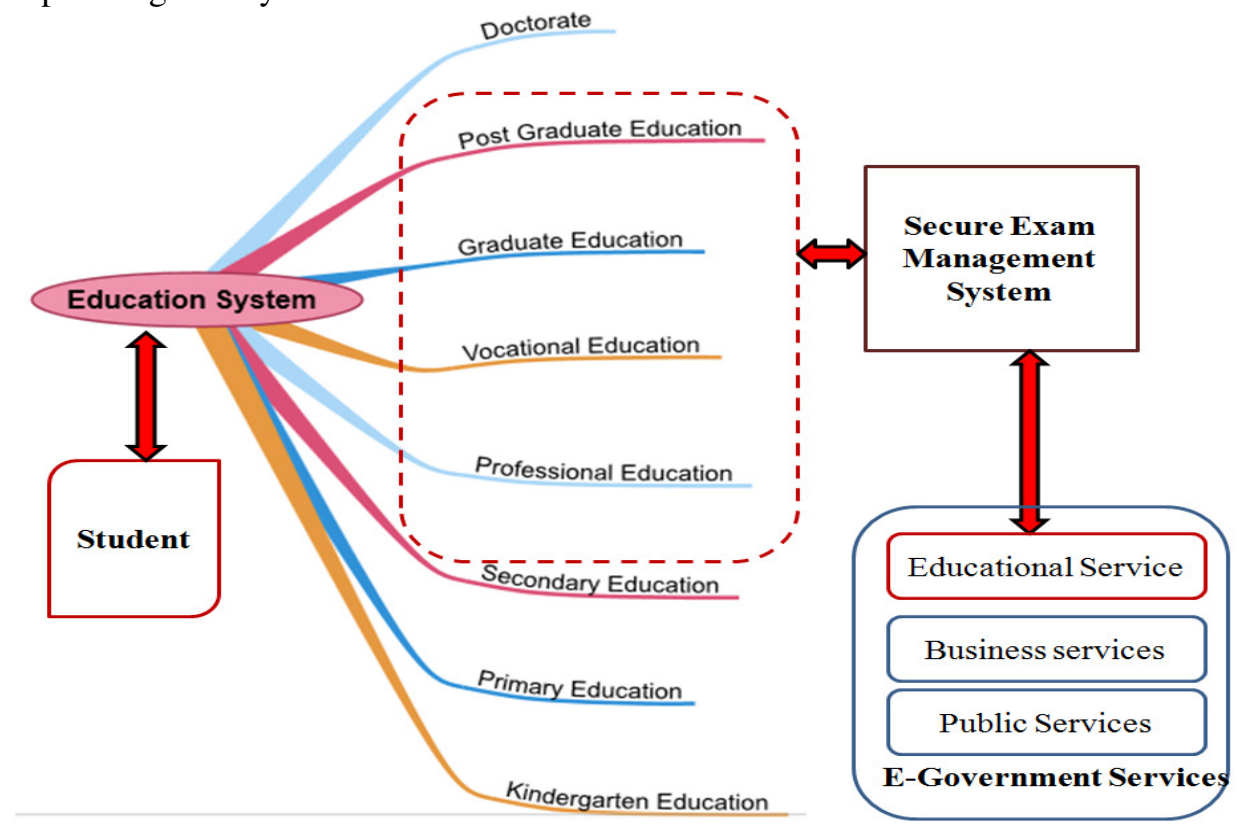

Fig.3. Framework for SEMS

The framework also addresses a lot of security related issues. Some of these concepts include proper way of using information: privacy, modification and availability. The use of these are 
making a genuine method of assets being stored, processed, and transmitted within and between e-government domains( government, education service, students, employees ) as shown in Fig.4.

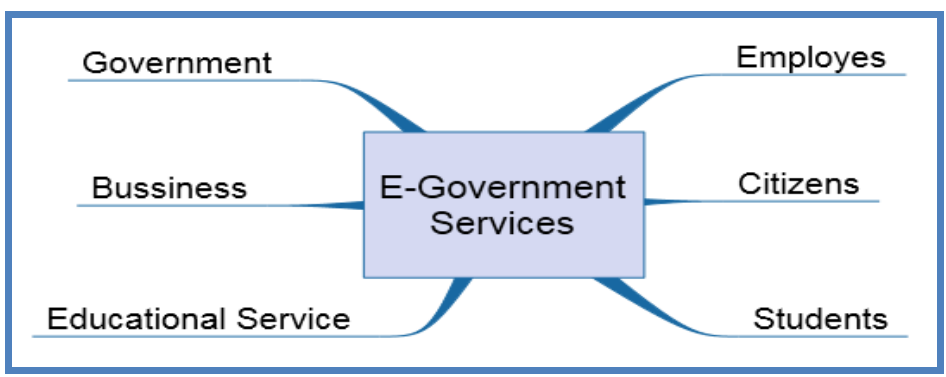

Fig.4. E-government service domains

\subsection{The Secure Exam Management System (SEMS)}

Examination system is one of the efficient methods for testing the ability of students in any education system. Examination is considered to be very crucial process in determining the progress and mostly about the understanding of subjects or courses of any academic activities. But currently examination is taken without properly identifying the target individuals, conducting the examinations and evaluating them. Using Secure Exam Management System (SEMS) these very weak methods of assessments and arrangements will be eliminated.

SEMS has been designed using cryptographic primitives, which enables students to attend examination from anywhere. The student is allowed to write exam only after his registration process has been completed and verified by the system for secure authentication purpose. In this system students are allowed to write objective and descriptive type examinations [9]. It allows evaluators to share student examination papers for evaluation with proper authentication. Instructors can design the model papers and conduct examinations with efficient security. SEMS is considered to be one of very important methods for faster, safer and efficient implementation of examination procedures for the progress of academic activities. Registering the users and identifying them as valid are the most important phases where security must be provided to the at most level. Examination paper will be generated at the time of examination so that reliability is maintained.

This paper is an effort towards attaining a good if not the best solution to the registration and identification of students in SEMS and provides confidentiality to question papers, answers, evaluation \& results. The answer papers are encrypted by using student's private key \& decrypted by using student's public key. The SEMS also supports the requirements, such as completeness, soundness, privacy, un-reusability, eligibility, fairness, authentication, confidentiality, receiptfreeness, non-duplication, public participation, and private error correction.

With the above requirements in mind, our goal was to develop a secure, user-friendly SEMS, which can be accessed anywhere from any place. Besides, there are three steps absolutely required for any of the examination system. These are registration, examination and evaluation.

1. For registration, the student must send user authentication details to SEMS, which goes to the appropriate administrator to his identity, prove for secure authentication, and stores that in server along with some essential authentication details.

2. For examination, the student can simply download the exam applet from his client system, and he need to provide his authentication details, and it is to be verified by the system. 
International Journal on Cybernetics \& Informatics (IJCI) Vol. 5, No. 4, August 2016

3. For evaluation, evaluators can share all the exam papers among themselves for perfection. The results announced without delay.

We also able to maintain a centralized database containing the details of all the students who have registered and they can be accessed from any client system, so that they can write examination from anywhere.

\subsection{System Design}

There are three main stages:

1. Registration

2. Examination

3. Evaluation

\section{Notation Used}

$\begin{array}{lll}\rightarrow \text { WAP } & : & \text { Wireless Application Protocol } \\ \rightarrow \text { AS } & : & \text { Admin server } \\ \rightarrow \text { EVS }: & \text { Evaluating server } \\ \rightarrow \text { ES }: & \text { Examination server } \\ \rightarrow \mathrm{Vi} \quad: & \text { Student } \mathrm{i} \\ \rightarrow \mathrm{vi} \quad: & \text { Examination selected by Student from mobile phone } \\ \rightarrow \mathrm{KU} & : & \text { Public key } \\ \rightarrow \mathrm{KR} & : & \text { Private key }\end{array}$

\section{Registration Stage}

Fig.5. shows the registration process of SEMS where students at the Examination server ( ES) accesses the AS to download the registration form and submit the authentication details. These details are encrypted with public key of WAP and then sent to AS. AS decrypts them with its private key. If the student signature does not match with the one at AS then, AS gives an error message. Otherwise the student is allowed to enter the examination stage.

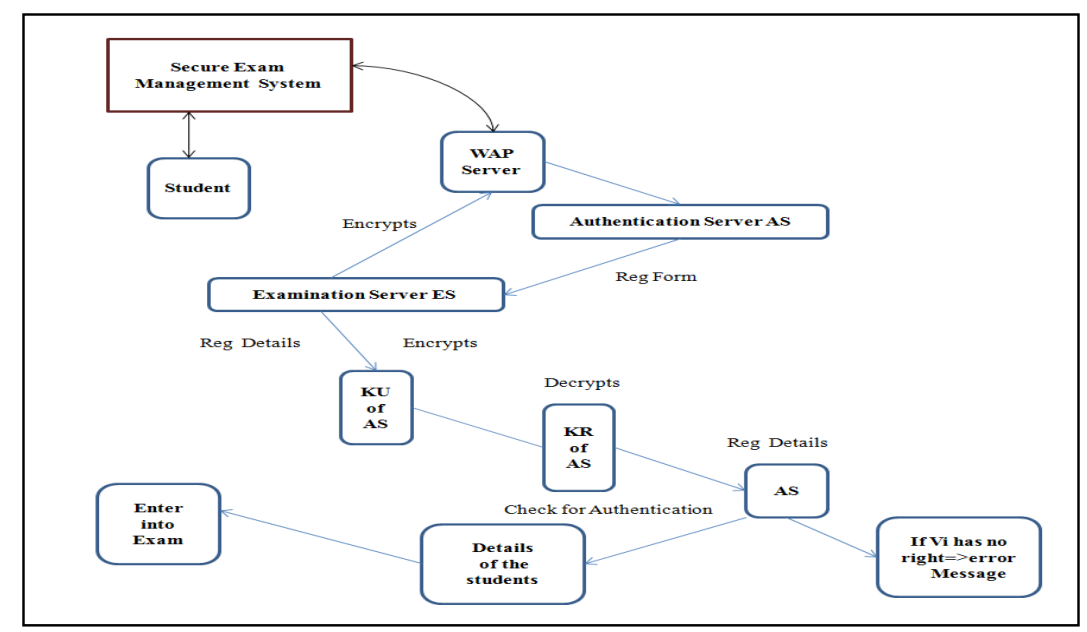

Fig.5. Registration Stage 


\section{Examination Stage}

In the examination stage as depicted in Fig.6, AS checks whether the student has previously was taken the examination or not. If the student has already taken the examination, AS rejects him or her. Otherwise the student is allowed to download the examination form. Then, the student selects an examination vi and this is encrypted with the public key of ES as xi. Encrypted examination xi is then blinded as ei. Examination ei is then signed by student as si and sent to AS. AS verifies the signature si of examination ei, if it is valid gives its signature to the examination ei as di. This is sent back to the student. Student retrieves the examination di and unbinds it to get yi. (xi, yi) is then sent to the ES.

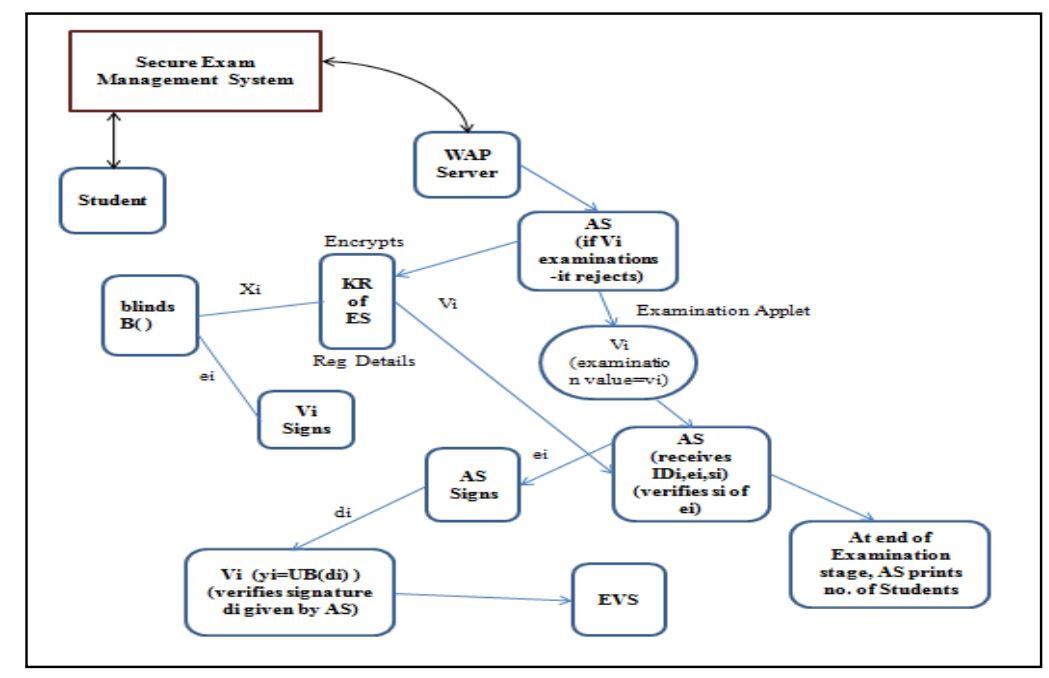

Fig.6. Examination Stage

\section{Evaluation Stage}

Fig.7 shows the evaluation process of SEMS, here EVS checks whether yi is valid signature of xi. If verification fails the examination is discarded. Otherwise EVS decrypts the examination xi with its private key and stores the examination results in the database. EVS publishes the examination results after the evaluation period is over. Students can view their results immediately after the evaluation process has been completed. 


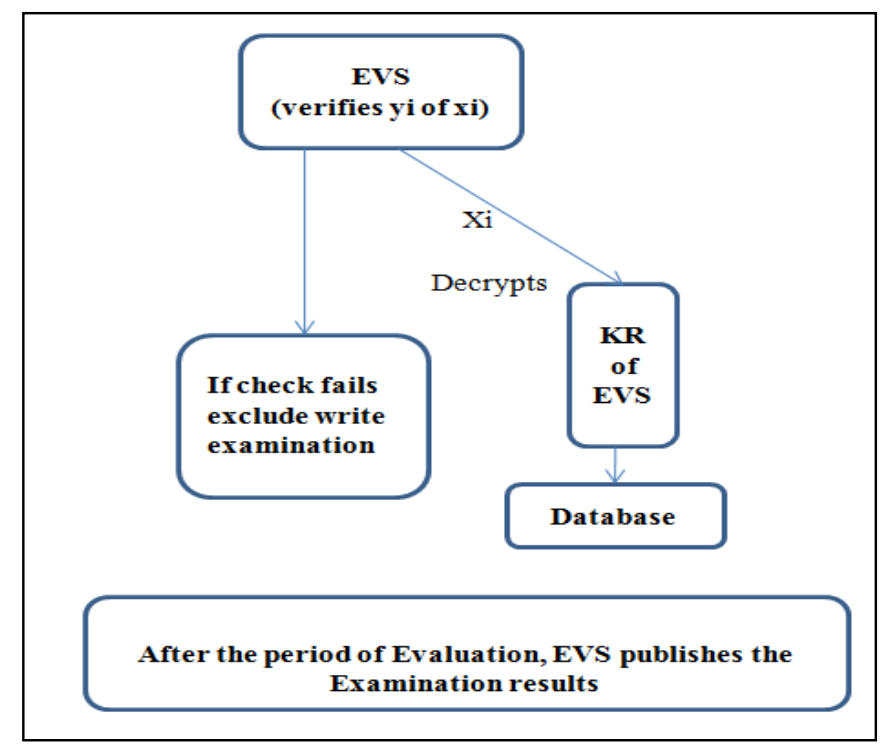

Fig.7. Evaluation Stage

\section{Conclusions}

This paper is aimed for developing a novel framework for integrating educational service with egovernment services. In doing so, we identified the problems seen in currently educational systems to conduct exams. A framework was proposed that facilitates delivering examination for all categories. Moreover, we designed a Secure Examination Management System (SEMS) that helps the eligible student to take examination from anywhere, make all the assessments processes very efficient, transparent for every one and also facilitates the students to know their results very fast. In essence, it will create a greater and smooth environment in the education system.

\section{ACKNOWLEDGEMENTS}

The authors would like to thank to God and the Electrical Engineering and computing School particularly the CSIT staffs and authorities of Addis Ababa Science and Technology University for their constant support and cooperation!.

\section{REFERENCES}

[1] Benefits, adoption barriers and myths of open data and open government / M. Janssen, Y. Charalabidis, A. Zuiderwijk, Information systems management v. 29, no. 4, p. 258-268. A Digital Single Market strategy for Europe / European Commission. 6 May 2015. COM(2015) 192 final.

[2] Lea Thiel, "Interplay between E-Government Service Adoption Preferences and E-Government Service Delivery in Germany" 2016 49th Hawaii International Conference on System Sciences.

[3] Adrião, Renato: "Best Practice Long Description: Portuguese Public eProcurement Program. Tampere 2006". http://www.4qconference.org/liitetiedostot/bp_long_descriptions/PortugalB_ long.pdf

[4] Anders Jacobi, Mikkel Lund Jensen, "Security of eGovernment Systems" http://www.ep.europa.eu/stoa/ 
[5] Michelle Selinger, Ana Sepulveda, Jim Buchan, "Education and Internet of Every Things", Cisco Consulting Services and Cisco EMEAR Education Team October, 2013.

[6] Steve Harrison, Antonis Tzounis, "A Security Evaluation Framework For U.K. E-Government Services Agile Software Development", International Journal of Network Security \& Its Applications (IJNSA) Vol.8, No.2, March 2016.

[7] Geoffrey Karokola, "Secure e-Government Services: Towards A Framework for Integrating IT Security Services into e-Government Maturity Models", 978-1-4577--1483-2/11/\$26.00 @2011 IEEE.

[8] Min-Shiang HWANG," Challenges in E-Government Security Information" ,Information Security, An International Journal vol.15,No.1,2004,09-20.

[9] G.Sanjiv Rao, "Activation of Secure Electronic Examination thru Mobile Communication", Second International Conference on Advanced Computing \& Communication Technologies, Track No TC14-06.

\section{AUTHORS}

Mr. Tesfayee Meshu is currently working as Head of the department of computer science \& IT, School of Electrical \& Computing, Addis Ababa Science and Technology University. He received his BSc in mathematics from Addis Ababa University and MSc in computer science from HiLCoE. His research interests include Software Engineering and Network protocols.

Dr. G. SanjivRao is currently working as Associate Professor in CS\&IT Department, School of Electrical \& Computing, Addis Ababa Institute of Science and Technology University. He received his Ph.D. from Dept of CS\&SE, College of Engineering Andhra University. His research areas include Coverage over Wireless Sensor Networks. Security and Privacy issues in Data Engineering, Network Security
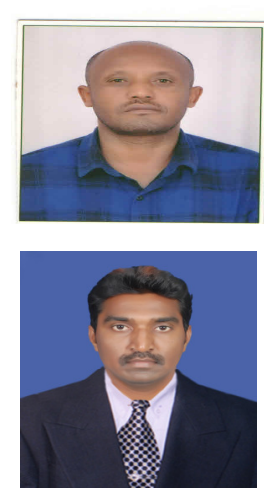